\title{
A PRODUÇÃO DIDÁTICA DE ROCHA POMBO: ANÁLISE DE HISTÓRIA DA AMÉRICA E NOSSA PÁTRIA
}

Juliana Golin Xavier Vianna

Orientação: Marcus Aurelio Taborda de Oliveira e Roseli Boschilia

PALAVRAS-CHAVE: Rocha Pombo; livro didático; história da educação.

José Francisco da Rocha Pombo foi um intelectual de grande atuação do Paraná dos fins do século XIX e início do século XX, como educador, historiador, jornalista, ensaísta, etc. Nasceu em Morretes em 1857, e neste local iniciou sua carreira atuando como professor e fundando o periódico O Povo. Mudou-se para Curitiba, já que era um centro intelectual mais promissor, onde passou a escrever artigos em jornais locais e livros, sobre diversos assuntos, como política, educação, história, literatura, etc. Em 1883 foi para Castro, onde iniciou sua breve carreira política, eleito deputado pelo Partido Conservador. Porém, sua carreira política não teve sucesso. Seu outro projeto fracassado foi o da criação da Universidade, e ambos os fracassos impulsionaram Rocha Pombo a deixar o Paraná. Em 1897 mudou-se para o Rio de Janeiro, onde desenvolveu sua carreira como historiador, com importantes obras historiográficas como Para a História e O Paraná no Centenário

Alguns historiadores já se dedicaram a estudar este destacado intelectual, a começar por seu contemporâneo Valfrido Piloto ${ }^{1}$. Este escreveu algumas obras de grande valorização da figura de Rocha Pombo. Com relação aos trabalhos mais recentes podemos destacar a tese de Névio de Campos ${ }^{2}$, que estudou os projetos de Universidade

\footnotetext{
${ }^{1}$ PILOTO, Valfrido. Rocha Pombo. Curitiba, 1953.

${ }^{2}$ CAMPOS, Névio de. Intelectuais Paranaenses e as Concepções de Universidade: 1892-1950. Tese (Doutorado em Educação) - Setor de Educação, Universidade Federal do Paraná, 2006.
} 
de Rocha Pombo, Gilson Queluz ${ }^{3}$, que atenta para as obras literárias, e Maria Tarcisa Silva Bega ${ }^{4}$, que publicou um artigo sobre a trajetória deste intelectual. São trabalhos muito importantes, porém deixam algumas lacunas, já que este autor teve tão vasta produção. Assim, este trabalho tem como objetivo auxiliar a preencher estas lacunas, com a análise de obras específicas, não pretendendo, entretanto, esgotá-las.

O presente trabalho nasceu como trabalho de Iniciação Científica no ano de 2008. Comecei então a estudar a trajetória e o pensamento de José Francisco da Rocha Pombo, com o objetivo de entender as concepções de educação deste intelectual. Durante esta pesquisa de IC me deparei com a vasta produção de Rocha Pombo, e, dentro deste universo os livros didáticos me chamaram atenção, por ser uma grande coleção e por sua heterogeneidade.

Diante desse acervo pouco explorado decidi prosseguir a pesquisa sobre a obra de Rocha Pombo, procurando, desta vez, investigar as concepções de história presentes nas obras didáticas produzidas pelo autor. Ao todo a coleção didática possui nove livros: quatro intitulados História do Brasil, a História Universal, História de São Paulo, História do Paraná, História da América e Nossa Pátria. Para este trabalho escolhi apenas duas destas obras, que me pareceram mais destacadas: História da América e Nossa Pátria.

O livro História da América foi o primeiro compêndio de Rocha Pombo, e o primeiro a tratar da América, escrito por um brasileiro. Foi publicado após vencer um concurso promovido pelo Conselho Superior da Instrução Pública do Distrito Federal, em 1897. Possui duas edições, a primeira de 1900 e a segunda de 1925. Para a análise desta obra utilizo ainda uma outra fonte, o parecer de Manuel

${ }^{3}$ QUELUZ, Gilson Leandro. Rocha Pombo: Romantismo e Utopias (1880-1905). Dissertação (Mestrado em Historia) - Setor de Ciências Humanas, Letras e Artes, Universidade Federal do Paraná, Curitiba, 1994.

${ }^{4}$ BEGA, Maria Tarcisa Silva. No centro e na periferia: a obra histórica de Rocha Pombo. In: LOPES, Marcos Antonio. (Org.) Grandes Nomes da História Intelectual. São Paulo: Contexto, 2003 
Bonfim sobre o resultado do concurso. Este texto está publicado no início da primeira edição da obra, e possui críticas, elogios e sugestões para o texto de Rocha Pombo.

O livro Nossa Pátria é o compêndio de mais sucesso do autor, tendo sido editado mais de 80 vezes. A data de sua primeira edição não é precisa, já que nesta época não era comum indicar o ano no próprio livro, mas acredito ser de $1917^{5}$. Também não se sabe o número exato de edições, mas temos informações de edições que vão até a década de 1940.

Quando iniciei esta pesquisa notei que os livros de Rocha Pombo foram muito importantes no Brasil, a partir de algumas evidências. Em primeiro lugar o grande número de obras, e o enorme número de edições da maioria destas obras. Também o fato de terem sido usados por mais de 30 anos, já que as edições mais recentes datam da década de 40. E, por fim, acredito que estas obras foram usadas em várias partes do Brasil, já que é possível encontrar hoje, pela internet, exemplares em sites de sebos e bibliotecas dos mais diferentes estados. Ainda com tantas evidências da relevância destas fontes, nunca antes tinham sido exploradas em um trabalho acadêmico.

Assim, os objetivos desta monografia são: 1- Compreender a importância da obra didática dentro da trajetória intelectual de Rocha Pombo. 2- Analisar os livros didáticos de História da América e Nossa Pátria, de Rocha Pombo, entendendo a narrativa presente nestas obras, comparando-as e observando em suas diferentes edições. 3- Compreender o pensamento do autor acerca da História, quais são os assuntos priorizados, quais são os fatos e atores mais relevantes, e qual o estilo que utiliza em sua narrativa.

A importância do estudo de livros didáticos como fontes históricas para entender o funcionamento das escolas e a cultura escolar no passado vem crescendo gradativamente. Temos acesso a diferentes trabalhos que tratam deste assunto, já que o livro didático é um dos materiais mais importantes no contexto escolar.

${ }^{5}$ Consta no catalogo on-line do acervo da Biblioteca Nacional: http://www.bn.br 
Temos presenciado atualmente debates não somente sobre o papel do livro didático, mas de toda a cultura material na educação dentro da história das disciplinas escolares. Uma disciplina escolar comporta não apenas as práticas docentes de aula e os conteúdos, mas também suas finalidades, seus materiais, suas práticas, seus exames ${ }^{6}$. Na historiografia mais tradicional, os elementos materiais da escola, como o livro, edifícios, mobília, são naturalizados, considerados elementos sem relevância ${ }^{7}$. Porém, hoje está surgindo uma nova discussão acerca da função destes elementos.

Circe Bittencourt afirma em sua tese de doutorado que o livro didático é o instrumento pedagógico mais utilizado no cotidiano escolar, sendo a principal fonte de estudo, e o produto cultural mais divulgado no Brasil entre as pessoas que possuem acesso a escola ${ }^{8}$. Chervel, quando fala da importância do conteúdo das disciplinas coloca em destaque a função do livro:

Dos diversos componentes de uma disciplina escolar, o primeiro na ordem cronológica, senão na ordem de importância, é a exposição pelo professor ou pelo manual de um conteúdo de conhecimentos. É esse componente que chama prioritariamente a atenção, pois é ele que a distingue de todas as modalidades não escolares de aprendizagem, as da família ou da sociedade ${ }^{9}$.

Note-se que Chervel posiciona a explicação do professor e o livro didático lado a lado, com a mesma função, de exposição dos conhecimentos. Assim temos o livro não só como o instrumento mais utilizado na escola, mas também como identificador do ensino escolar, em primeiro lugar, e, em segundo como identificador da

${ }^{6}$ CHERVEL, André. História das Disciplinas Escolares: reflexões sobre um campo de pesquisa. In: Teoria e Educação, Porto Alegre, n. 2, 1990.

7 SOUZA, Rosa Fátima de. A cultura material na história da educação: possibilidades de pesquisa. Revista Brasileira de História da Educação, n. 14, SBHE, 2007.

${ }^{8}$ FONSECA, S. G. Livros didáticos e paradidáticos de História. In: Didática e Prática de Ensino de História. 5.ed. São Paulo: Papirus, 2006.

${ }^{9}$ CHERVEL, op. cit., p. 202. 
própria disciplina. Este autor afirma ainda que as fronteiras entre as diversas disciplinas são traçadas por programas, horários, didáticas, pela formação dos professores ${ }^{10}$, e também, é claro, pelo material didático. Essas fronteiras são criações dos determinados contextos históricos, e, portanto, mutáveis.

Este caráter mutável da disciplina escolar também é discutido por Dominique Julia, que afirma que não se pode considerar que a disciplina escolar é exatamente a mesma com o passar do tempo apenas por possuir o mesmo título. A "História” ensinada nas escolas do fim do século XIX e início do XX não é exatamente a mesma que a "História" atualmente ensinada nas escolas. É preciso observar as mudanças de finalidades e conteúdos:

(...) toda a história das disciplinas escolares deve, em um mesmo movimento, considerar as finalidades óbvias ou implícitas buscadas, os conteúdos de ensino e a apropriação realizada pelos alunos, tal como pode ser medida por meio de seus trabalhos e exercícios ${ }^{11}$.

Há aspectos na obra didática de Rocha Pombo que evidenciam isto. Todos os seus compêndios trazem extensas descrições de clima, relevo, hidrografia, fauna e flora. Isto causa um inicial estranhamento para nós hoje, que usamos, em nossa escolarização, livros que foram escritos cerca de 100 anos depois. A divisão didática que estamos acostumados a ver nos livros mais atuais não trariam estas discussões na disciplina de História. Estariam provavelmente contemplados na disciplina de geografia, ou ainda biologia, para as questões de fauna e flora.

Isto nos faz lembrar que as disciplinas escolares e o currículo como um todo são "construtos sócio culturais, historicamente

\footnotetext{
${ }^{10}$ Ibid., p.213.

11 JULIÁ, Dominique. Disciplinas escolares: objetivos, ensino e apropriação. In: LOPES, A. C.; MACEDO, E. (Orgs.) Disciplinas e Integração Curricular: história e políticas. Rio de Janeiro: DP\&A, 2002, p. 51.
} 
contingentes”12. Isso significa que as disciplinas e seus conteúdos, práticas, avaliações, exercícios, estão em constante modificação, como neste caso fica claro o caso da história. A partir do momento em que um conhecimento é trazido para escola, ele deve se “encaixar" dentro de uma determinada disciplina, e esta escolha é feita a partir de diversos aspectos contextuais. A escolha do detalhamento da fauna, flora, clima, relevo brasileiros no livro didático de história é certamente um fato a ser observado, já que hoje, nas escolas, são elementos de outras disciplinas, mas que em nenhum momento deixaram de ser relevantes para história.

Outro papel importante do livro didático é ser um dos elementos fundamentais no processo de ensino e na definição do currículo, além de, no caso da História, ser o principal canal de difusão de seus saberes específicos ${ }^{13}$. A escola está em diálogo com a produção do saber histórico, formulando, construindo e selecionando o conhecimento histórico que deve compor o livro didático. Assim, principalmente no início do século XX (e até hoje), os conteúdos a serem ensinados na escola nas determinadas séries eram aqueles encontrados nos compêndios.

A análise de livros didáticos também não deve deixar de levar em conta que se trata de um produto da indústria cultural, como já enunciado. Os livros de Rocha Pombo são alguns dos primeiros de História escritos no Brasil por brasileiros, mas possuíam os concorrentes estrangeiros, que eram muito mais utilizados e aceitos. Deve-se procurar entendê-los não apenas com relação ao seu conteúdo, mas também seus procedimentos de produção, difusão, circulação, escolha e aquisição ${ }^{14}$.

TABORDA DE OLIVEIRA, Marcus Aurélio. Educando pelo corpo: saberes e práticas na instrução pública primária nos anos finais do século XIX. In: BENCOSTTA, Marcus Levy Albino (org). Culturas escolares, saberes e práticas educativas: itinerários históricos. São Paulo: Cortez, 2007, p. 266.

${ }^{13}$ FONSECA, op. cit..

14 MUNAKATA, K. O livro didático e o professor: entre a ortodoxia e a apropriação. In: MONTEIRO, A., GASPARELLO, A e MAGALHAES, M (orgs). 
Para a análise das fontes selecionadas para esta pesquisa é também importante entender como Rocha Pombo concebe e constrói a História. Para isto, utilizo uma fonte secundária, o prefácio do primeiro volume da História do Brasil, em que Rocha Pombo escreveu sobre “A Concepção Moderna da História”. Nesta obra o autor acredita que a História é uma ciência, já que pode-se "ordenar os phenomenos que se manifestam nos aggrupamentos humanos isolados; si já nos habilitamos a systematizar factos relativos á vida e ao desenvolvimento de uma nação." 15 As leis aplicadas as demais ciências sociais podem virar leis históricas. Em um dos trechos, por exemplo, Rocha Pombo menciona o conceito de progresso. Em nota, o autor ainda explica aquilo que entende por progresso: os avanços que fazem os intelectuais, com suas descobertas e idéias, é o "trabalho de ir passando para o domínio das collectividades as conquistas que vão fazendo os indivíduos mais capazes de esforço intellectual”16. É interessante notar aqui que, ao contrário de muitos autores da época que pensavam o progresso como um avanço material, Rocha Pombo se preocupa muito com o avanço intelectual e moral, daí sua grande atenção com a História e a Educação, que são dois campos que desenvolvem este avanço moral e intelectual. Segundo o autor, o que faz com que a História não pareça uma ciência é essa aparente desordem, que faz acreditarmos que tudo é eventual na vida dos povos. Mas, conforme os intelectuais vão avançando, vai-se percebendo as relações, a ordem, e a sistematização da História.

É também importante saber que Rocha Pombo não realizava pesquisas baseadas em fontes primárias. Este é um elemento relevante para compreender seu pensamento acerca da História. Ele mesmo reconhecia a importância da visita aos arquivos na Europa, mas

Ensino de História: sujeitos, saberes e praticas. Rio de Janeiro: Mauad X; FAPERJ, 2007.

${ }^{15}$ ROCHA POMBO. Prefácio. In: História do Brasil. 10 v. Rio de Janeiro: JF Saraiva e C. Editores, [1905-1030].

${ }^{16}$ Ibid., p. VIII. 
lamentava não possuir a oportunidade de fazê-lo, ${ }^{17}$ e sua justificativa para tal era a falta de recursos.

A obra História da América é um livro didático que foi publicado duas vezes, nos anos de 1900 e 1925. Seu texto foi escrito para um concurso promovido pelo Estado para obras didáticas de história que tratassem da América. Para o presente trabalho tive acesso as seguintes fontes: o parecer de Manuel Bonfim, que aprova o texto de Rocha Pombo no concurso; e as duas edições do livro. Assim, trato de três versões do texto desta obra, escritos por Rocha Pombo: 1- o manuscrito inicial não publicado, que é o texto que foi submetido ao concurso, antes de ser avaliado e aceito. Não tive acesso a este texto, mas deduzo seu conteúdo a partir das críticas de Bonfim; 2- a primeira edição, já alterado pelas sugestões de Bonfim; 3- a segunda edição, com algumas alterações em relação a primeira.

Manuel Bonfim era, neste momento, professor de Educação Moral e Cívica na Escola Normal do Rio de Janeiro, e posteriormente tornar-se-ia diretor da Instrução Pública, além de também ser autor de livros didáticos de história. Tece muitos elogios a narrativa de Rocha Pombo, afirmando que este escreve história como os clássicos, e sua escrita apaixonada comove o leitor. Valoriza a visão de moralidade, que é a visão da colonização como exploração, como um saque. Os portugueses e espanhóis não teriam vindo a América com objetivos de se estabelecer, mas de tomar destas terras tudo o que podiam para se beneficiar, tomar as riquezas dos povos que aqui encontraram e ainda escravizá-los criando um conflito entre o colono e o nativo. Bonfim observa ainda que esta postura não era individual dos colonos, mas incentivada pelo Estado espanhol, que lucrava muito com as arrecadações. Faz ainda uma comparação com a colonização da América do Norte, que teria sido mais estável, por indivíduos que

${ }^{17}$ NESTOR VITOR. Obra Crítica. v. 3. Rio de Janeiro/Curitiba: Fundação Casa Rui Barbosa/ Secretaria do Estado da Cultura e do Esporte, 1979. p.6. 
buscavam "a paz e a liberdade espiritual, individuos que traziam o firme propósito de crear aqui uma segunda patria”18.

Esta é a principal característica da obra: a visão crítica do autor com relação ao papel dos europeus na América. O passado colonial da América é visto como um passado vicioso, feito por pessoas de mau caráter. Porém, esta visão não se repete nos demais compêndios do autor. No livro Nossa Pátria, por exemplo, os europeus aparecem como heróis. O número de edições de História da América é muito pequeno, quando comparada com as demais obras do mesmo autor, o que pode indicar um fracasso deste projeto. A mudança do discurso nos demais livros também pode ser resultado deste fracasso. Mas também é preciso lembrar que não existiam comumente disciplinas exclusivas de História da América, para o consumo desta obra.

Cria-se também, nesta obra, um discurso da necessidade da criação de um sentimento de "fraternidade" dos povos americanos, para buscarmos a união dos países americanos, ressaltando nosso amor pela liberdade, e dando nova feição ao nosso civismo. Tudo isto em oposição aos europeus. Há também uma grande valorização da América do Norte como exemplo a ser seguindo.

O livro didático Nossa Pátria possui características muito diversas do livro anteriormente comentado. Trata-se de um livro muito menor, com uma linguagem adaptada a um público infantil, com muitas imagens, letras grandes e idéias repetitivas e pouco desenvolvidas. Seu caráter mais marcante é a formação de um sentimento de pátria e a valorização do passado legitimador do nosso país.

O livro inicia mostrando ao leitor os motivos para que se orgulhem do seu país: o fato de os homens que aqui vivem são aqueles com quem temos contato, possuem os mesmos antepassados, as mesmas morais e a mesma língua. E ainda destaca a necessidade de defendermos nosso país no caso de invasões dos países invejosos.

${ }^{18}$ BONFIM, Manuel. Parecer. In: ROCHA POMBO. História da América. 1. Ed. São Paulo: Laemmert \& C. Editores, 1900. 
Há uma grande valorização dos símbolos da pátria como a hino, o escudo de armas, mas principalmente a bandeira, que é descrita com detalhes, e aparece em diversas partes do livro como ilustração. Afirma Rocha Pombo que só possuem bandeira nacional aqueles países que são livres e não obedecem a outros, portanto, há uma grande valorização da emancipação brasileira, afirmando que "é este - o da nossa independencia - o facto mais notavel da nossa historia". E de fato todos os elementos da história brasileira presentes nesta obra são como uma preparação ou como conseqüência da independência.

Assim como em História da América há uma grande valorização dos "heróis", figuras simbólicas e virtuosas que contribuíram pessoalmente com nossa história. Em alguns pontos da narrativa a história do Brasil (ou da América) são resumidas as trajetórias e ações pessoais destes personagens. São comumente descritos como homens "a frente do seu tempo", que agiam por si apenas, mudando o rumo dos acontecimentos. Alguns destes personagens destacados são Colombo, Cabral, José Bonifácio, D. Pedro II, dentre outros.

Com relação a visão dos europeus há uma grande diferença daquela empregada em História da América. O europeu é apresentado como um ser pacífico que resolve seus problemas com a razão e o direito. Não menciona Rocha Pombo nesta obra a violência com que os índios foram escravizados e dizimados pelos brancos. A questão da escravidão indígena aparece porque, segundo o autor, os portugueses chamaram os índios para ajudá-los no cultivo das terras e estes se recusaram, o que fez com que fossem escravizados. Os índios são caracterizados como "inferiores" aos europeus, e os negros são vistos como passivos, mas importantes para o progresso brasileiro por seu trabalho.

Esta obra possui este caráter ufanista e otimista por se tratar de um livro específico da construção do sentimento pátrio. Não se trata de uma construção da História do Brasil apenas, mas da história da 
Pátria, e para criar um sentimento de pátria o autor recorre a um discurso de grande valorização do passado.

Outra característica importante desta obra é a posição do Brasil com relação aos demais países da América do Sul. A idéia de fraternidade é mantida, entretanto, neste compêndio o Brasil aparece com um papel de mantenedor da democracia e da justiça, tendo que interferir nos outros países por este objetivo, na Guerra da Cisplatina e na Guerra do Paraguai.

Este trabalho foi dividido em três capítulos. Na introdução há uma discussão acerca do uso do livro didático como fonte histórica, e sua relevância para entendermos o contexto escolar de uma determinada época. O primeiro capítulo trata da trajetória deste intelectual, e suas concepções de História e Educação. Os demais capítulos são dedicados a análises das duas obras escolhidas, sendo que o segundo capítulo enfoca a obra História da América, e o terceiro a Nossa Pátria. 